\title{
Movimentos sociais e transformação societária: concepções teóricas presentes na tradição marxista
}

\author{
Maria Clariça Ribeiro Guimarães \\ Universidade Federal do Rio Grande do Norte (UFRN)
}

\author{
Eliana Costa Guerra \\ Universidade Federal do Rio Grande do Norte (UFRN)
}

Movimentos sociais e transformação societária: concepções teóricas presentes na tradição marxista
Resumo: Este ensaio tem como objetivo discutir premissas de análise da temática movimentos sociais e transformação societária
presentes na formulação marxista. Para tanto, retoma o pensamento de autores clássicos, em especial, Lênin, Rosa Luxemburgo e
Gramsci. Destaca, com base nesses autores, as determinações fundamentais para a análise das lutas sociais da classe trabalhadora,
enfatizando a teoria da organização, a ampla participação das massas e a construção de uma nova hegemonia.
Palavras-chave: Movimentos sociais. Transformação societária. Tradição marxista.

Social Movements and Social Transformation: theoretical concepts in the Marxist tradition

Abstract: The purpose of this essay is to discuss the premises of the analysis of the theme social movements and social transformation found in the Marxist formulation. To do so, it looks at the work of classic authors, particularly Lenin, Rosa Luxemburg and Gramsci. It highlights, based on these authors, the determinations fundamental to the analysis of the social struggles of the working class, emphasizing the theory of organization, the broad participation of the masses and the construction of a new hegemony.

Keywords: Social movements. Social transformation. Marxist tradition. 


\section{Introdução}

Em um contexto marcado por grandes lutas nos anos 1960, os movimentos sociais tornam-se objeto de estudo acadêmico, nas mais diversas abordagens teórico-metodológicas. Isto indica que a realidade define, em grande medida, a agenda de pesquisa da universidade, mas segue as escolhas políticas e teórico-metodológicas dos sujeitos pesquisadores.

Entre as teorizações de maior influência na produção teórica brasileira acerca dos movimentos atuais, também designados "novos" movimentos sociais, a exemplo do paradigma europeu, destacamos três principais vertentes: a abordagem culturalista-acionalista, o pensamento pós-moderno e o paradigma marxista.

A teoria culturalista-acionalista enfatiza a cultura, a identidade e a solidariedade entre as pessoas de determinado movimento social. Segundo esta perspectiva, os movimentos contemporâneos apresentam interesses difusos e não classistas. Por isso mesmo, há um redirecionamento do eixo central das demandas postas na esfera pública, as quais são deslocadas do campo da economia para o campo da cultura. Nesta abordagem, a ênfase está no papel dos indivíduos e não no da classe social e, na mesma lógica, os movimentos são vistos muito mais como agentes de pressão do que de transformação societária (TOURAINE, 1989). Trata-se, portanto, de uma teoria que procura explicar a ação coletiva em uma perspectiva subjetivista dos fenômenos.

A exemplo do que ocorre com a perspectiva acionalista, também para o pensamento pós-moderno e neoconservador, os "novos movimentos sociais" são analisados como distantes e apartados da contradição capital-trabalho. Além de afirmar a perda da centralidade dos conflitos de classe no processo de organização e de ação política dos movimentos sociais, assegura ainda a inexistência de tais conflitos na contemporaneidade (LACLAU; MOUFFE, 1988). Em uma total negação das bases teóricas clássicas do marxismo, a leitura pós-moderna dos movimentos sociais não acredita em qualquer perspectiva de contraponto aos interesses do capital e de emancipação do trabalho. Ainda que questione e nivele os referenciais marxista e positivista, o principal embate é contra a teoria social de Marx, cuja novidade na literatura contemporânea é a introdução dos recortes de gênero, etnia e geração, sem abandonar a perspectiva das lutas de classe.

Dado os limites do presente texto, privilegiamos a abordagem marxista referente aos movimentos sociais ${ }^{1}$ devido a sua perspectiva de totalidade, importante para apreender o real em suas múltiplas determinações, articulando aparência e essência em sua relação dialética.

\section{O marxismo na batalha das ideias}

Retomamos aqui a expressão do militante e pensador marxista Leandro Konder (2009) - que dá título a um de seus livros - para ressaltar a dificuldade em insistir na filiação à tradição marxista e na análise dos movimentos sociais em um momento em que o pensamento social brasileiro se defronta com convites constantes para a fragmentação da realidade e a negação de sua totalidade. Braz (2011) chama a atenção para tendências à oscilação entre o catastrofismo fatalista, o esquerdismo pós-moderno e a cultura do possibilismo: ora afirma-se não haver o que fazer, ora se dilui a luta de classes em múltiplos particularismos, ou ainda, aposta-se na colaboração de classes como alternativa. Tais posições questionam ou mesmo negam os processos de luta do proletariado por uma sociedade livre da exploração de classe.

Boaventura de Sousa Santos (1999, 2005), expoente da intelectualidade pós-moderna, talvez seja a melhor tradução, neste momento, para ilustrar o descrédito tão amplamente difundido quanto às possibilidades de transformação societária radical:

[...] a primazia explicativa das classes é muito mais defensável que a primazia transformadora. Quanto a esta última, a prova histórica parece ser por demais concludente quanto à sua indefensabilidade. Dando de barato que é fácil definir e delimitar a classe operária, é muito duvidoso que ela tenha interesse no tipo de transformação socialista que lhe foi atribuído pelo marxismo e, mesmo admitindo que tenha esse interesse, é ainda mais duvidoso que ela tenha capacidade para o concretizar. Essa indicação que parece hoje indiscutível tem levado muitos a concluir pela impossibilidade ou pela indesejabilidade de uma alternativa socialista (SANTOS, 1999, p. 41).

O fim de qualquer possibilidade de construção de alternativas a esta sociabilidade está longe de ser indiscutível, dado o caráter histórico e criador da práxis humana. Reproduzir o discurso generalizado de impossibilidade de transformação societária significa contribuir para a produção de uma cultura de passividades e conformismos, diretamente incidente no cotidiano da classe trabalhadora, resultando em um evidente reforço da alienação, em detrimento de projetos de natureza coletiva. 
Atualmente, defrontamo-nos, portanto, com duas grandes tendências teóricas que vêm incitando a "batalha das ideias": uma vinculada ao conservadorismo, inspirada nas tendências pós-modernas, a compreender a realidade social como um campo de fragmentos e os movimentos contemporâneos como espaços de interesses difusos e não classistas; outra, vinculada à tradição marxista, a entender a realidade a partir de uma perspectiva histórico-ontológica, buscando abranger as determinações objetivas e subjetivas dos processos sociais² ${ }^{2}$.

Na formulação de Marx e Engels (2008), a compreensão teórica do movimento histórico reivindica que, até hoje, a história da humanidade é a história da luta de classes. A constituição das classes sociais, medular e historicamente, decorre da forma através da qual os sujeitos organizam-se para e pelo trabalho e garantem a (re)produção social de uma determinada sociedade.

$\mathrm{Na}$ atual lógica societal, a realização do trabalho e as relações sociais por ele suscitadas, materializamse real e idealmente de forma alienante. Isso não atesta, entretanto, a total ausência de mediações e de

Reproduzir o discurso generalizado de impossibilidade de transformação societária significa contribuir para a produção de uma cultura de passividades e conformismos, diretamente incidente no cotidiano da classe trabalhadora, resultando em um evidente reforço da alienação, em detrimento de projetos de natureza coletiva. possibilidades emancipatórias que proporcionem condições para os indivíduos superarem tal ordem societária, inclusive, porque a própria condição de exploração suscita formas de rebeldia e resistência.

Não por acaso, a tradição marxista atribui significativa importância à ação coletiva da classe trabalhadora por meio dos diversos instrumentos político-organizativos. Em $O$ manifesto do partido comunista, Marx e Engels destacam que, em uma sociedade marcada pela divisão de classes, os interesses antagônicos impulsionam a política por meio do enfrentamento de forças entre as classes.

A abordagem marxista dos movimentos sociais, cuja matriz situa-se no conflito capital-trabalho, privilegia o processo de luta histórica das classes subalternas. Isto não significa limitar-se à análise do movimento operário, relegando a um segundo plano outros movimentos políticos; tampouco implica em trabalhar com determinações exclusivamente econômicas, pois a opressão-dominação capitalista perpassa as mais diversas dimensões da existência social. O grande diferencial do paradigma marxista na análise dos movimentos sociais consiste em possibilitar apreender, para além dos aspectos imediatos, a essência dos fenômenos e a contraditória relação entre essência e aparência. Nesta teoria, há também a preocupação frequente em subsidiar a ação política destes movimentos e, assim, contribuir para a práxis revolucionária. Resulta daí o fato de tal paradigma ter provocado e impulsionado, ao longo da história, não somente o desenvolvimento de um amplo universo teórico e analítico em torno do processo revolucionário e das estratégias de transição socialista, como também suscitado e fundamentado a construção de diversos instrumentos político-organizativos da classe trabalhadora.

Fundamentalmente, como destaca Gohn (2007, p. 173),

[...] as teorias marxistas sobre os movimentos sociais não abandonaram a problemática das classes sociais. Ela [a problemática das classes] é utilizada para refletir sobre a origem dos participantes, os interesses do movimento, assim como o programa ideológico que fundamenta suas ações.

Do ponto de vista teórico, a análise marxista dos movimentos sociais compreende interlocuções privilegiadas, como as elaborações clássicas de Lênin (1961, 1975, 2010, 2006, 1980), Rosa Luxemburgo (1991, 2005) e Gramsci (1999-2002) que, sob diferentes prismas, contribuíram para o entendimento do conteúdo político expresso na ação dos movimentos sociais, tendo como referência os processos sociais engendrados em cada tempo histórico.

Por certo, o próprio desenvolvimento das forças produtivas inscrito na particularidade de cada formação social em determinado período, produz novas necessidades, gera novas determinações a constituir desafios e a interpelar pesquisadores e teóricos no sentido de desvendar e apreender o real em sua contraditoriedade e na relação singularidade-universalidade-particularidade. Ora, o caráter de construção histórica da organização política requer o exame concreto da atuação dos movimentos sociais em cada conjuntura para compreender os 
diferentes conteúdos e formas que assumem suas mobilizações e lutas e, desse modo, não atribuir aos movimentos sociais, independentemente do contexto histórico no qual estão situadas ações e táticas políticas, únicas e imutáveis (GUIMARÃES, 2011).

Embora as elaborações em questão constituam desdobramentos das ideias fundantes de Marx e Engels (2008), elas trazem imbricadas em si as necessidades expressas pela luta de classes, no contexto em que cada um destes autores exerceu, ao mesmo tempo, a atividade de pensador e militante, teórico e dirigente político. É o que veremos a seguir.

\section{Lênin: teoria da organização e questões práticas no processo de transformação social}

Lênin centra seus estudos políticos em questões práticas passíveis de serem evidenciadas no processo de transformação político-revolucionária, especialmente, a teoria da organização, sobre a qual são exemplares as obras: Que fazer? (2010) e Carta a um camarada (2006).

Com base em Salem (2008), destacamos, inicialmente, a tese segundo a qual a guerra nada mais é que a continuação da política gerida pelas classes dominantes, através de meios distintos daqueles mais usuais. Ao comparar a política à arte militar, Lênin evidencia a necessidade dos socialistas tecerem estudos e análises a respeito de cada guerra, em particular, tendo em mente que somente a revolução do proletariado pode deitar fim a todas as guerras, em geral. Por exemplo, o sentido de um período histórico revolucionário para a social-democracia pode ser comparado ao significado de uma guerra para o exército. Nos dois casos, em determinado momento, interpõe-se a necessidade de multiplicação dos quadros, mobilização das diversas forças e adoção de distintos processos de luta (LÊNIN, 2010), capazes de responder ao ataque inimigo; pode ocorrer ainda a necessidade de saber recuar em algum momento, como passo importante para conquistas mais adiante.

Nesta acepção, uma revolução política constitui também, e sobretudo, uma revolução social, uma mudança na situação das classes que compõem a sociedade, especialmente porque é síntese de múltiplas contradições acumuladas durante um longo período histórico. Traduz o fim de uma superestrutura que já não mais corresponde às relações de produção estabelecidas. Por isso, para Lênin, a revolução não pode nem ser "provocada por encomenda", tampouco ser indefinidamente protelada ${ }^{3}$. Do mesmo modo, a ocorrência da revolução proletária não representa de forma alguma uma verdade dada, pré-determinada e inquestionável. Lênin ressalta a influência de diversos outros elementos da conjuntura social e política, para além do esgotamento das condições do desenvolvimento econômico e social face à superestrutura vigente. Elementos como a própria força e o nível de consciência e organização do proletariado cumprem papel importante no desencadeamento dos processos revolucionários.

Uma revolução é feita por uma série de batalhas. Na ótica leninista, cabe ao partido de vanguarda fornecer em cada etapa uma palavra de ordem adaptada à situação objetiva e ainda reconhecer o momento oportuno para a insurreição. Perceber a revolução como uma série de batalhas constitui um evidente contraponto à noção ingênua de revolução como um ato único, ou única batalha, facilmente desenvolvido e sem grandes contratempos. A revolução pressupõe uma nova concepção de história, capaz de percebê-la como um processo complexo e contraditório, jamais linear ou passível de se realizar somente em condições totalmente favoráveis (LÊNIN, 1961, 1975). Na leitura de Lênin, encontra-se também a ideia de vanguarda do partido na condução do movimento político das massas. Todavia, isto não representa negação da dimensão política presente na prática dos movimentos sociais, pois ele admite que a revolução depende, em primeiro lugar, da classe e não do partido, como podemos verificar em sua Carta ao Comitê Central do Partido Operário Social-Democrata Russo (POSDR): "para ter êxito, a insurreição deve se apoiar não numa conjura, não num partido, mas na classe avançada. Isso em primeiro lugar. A insurreição deve se apoiar no ascenso revolucionário do povo" (LÊNIN, 1980, p. 308).

Lênin faz tal afirmação em um contexto de insurreição, não podendo ser descontextualizada e interpretada desconsiderando as determinações histórico-conjunturais em que foi forjada. Caso contrário, poderíamos incorrer em um deslize autonomista que não corresponde ao seu pensamento. O partido político é condição e instrumento sem o qual não há revolução; é a partir dele que as massas articulam seu projeto de libertação para avançar. Lênin $(2006,2010)$ refere-se ainda à necessidade da ditadura do proletariado, na condição de classe revolucionária, para o desenvolvimento da revolução; ou seja, a necessidade de substituição do Estado burguês pelo Estado proletário, durante o período de transição para uma sociedade comunista.

No percurso da história, os socialistas não podem renunciar à luta pelas reformas, tampouco podem permanecer limitados a estas. Ao contrário, trata-se de perceber a importância da defesa de quaisquer melhorias, ainda que mínimas, na condição de vida e de trabalho das massas, ressalvada a necessidade de articulação com a luta anticapitalista e com a revolução proletária. A luta por melhorias não pode suplantar a luta anticapitalista. 
O legado teórico-político de Lênin configura-se como uma contribuição às diretrizes da organização partidária e às linhas de construção do partido de ação revolucionária, capaz de orientar e conduzir a luta de classes, aglutinando os revolucionários e os organizando em torno das tarefas imediatas.

\section{Rosa Luxemburgo: a ampla participação das massas no processo de transformação social}

No campo da disputa de ideias, Rosa Luxemburgo dedica-se, prioritariamente, a construir o contraponto às noções reformistas que negavam a necessidade da revolução e defendiam uma possível transição ao socialismo via a realização de reformas graduais do capitalismo. Dentre as contribuições específicas de Luxemburgo para as teorias dos movimentos sociais, destacamos as análises da ampla participação das massas no processo de transformação social. Em seu clássico texto Greve de massas, partido e sindicatos, sinaliza, a partir da experiência russa, a greve de massas como estratégia importante na luta por direitos políticos. Evidencia, todavia, que a greve deve ser percebida como um produto histórico e não artificial. Assim, a greve de massas não se apresenta como uma decisão, mas como uma necessidade histórica; seu curso constitui excelente oportunidade para intensificar a agitação revolucionária. Por conseguinte, uma simples luta econômica por salários pode tomar proporções de um importante fenômeno político. Da mesma forma, a luta política pode potencializar a luta econômica, em um movimento de relação permanente entre ambas, resultante do fato de:

As greves políticas e as econômicas, as greves de massas e as parciais, as greves de protesto e as de luta, as greves gerais de determinados ramos da indústria e as greves gerais em determinadas cidades, as pacíficas lutas salariais e os massacres nas ruas, as batalhas nas barricadas: todas se entrecruzam, correm paralelas, se encontram, se interpenetram e se superpõem; é uma variável onda de fenômenos em contínuo movimento. E a lei que determina o movimento desses fenômenos é clara: não se encontra na greve de massas em si mesma nem em suas particularidades, mas, sim, na dimensão política e social da força da revolução (LUXEMBURGO, 2005, p. 282).

Para Rosa Luxemburgo, pelo menos três aspectos gerais devem ser considerados para uma coerente análise da greve de massas. O primeiro reporta-se ao fato desta não consistir, de modo algum, numa ação isolada. A impossibilidade prática de estabelecer uma linha divisória entre os elementos da luta política e os elementos da luta econômica constitui o segundo aspecto, igualmente relevante. Este entendimento aplica-se não apenas a cada uma das greves de massas, mas também à revolução em seu conjunto, que é, ao mesmo tempo e simultaneamente, econômica e política. $\mathrm{O}$ terceiro aspecto refere-se ao caráter assumido pela greve de massas, inseparável da revolução, entendida como expressão, sobretudo, do resultado de uma completa transformação das relações sociais de classe. $\mathrm{O}$ fator espontaneidade assume um importante papel nos processos de luta, constituindo um dentre tantos fatores passíveis de desencadear a consciência de classe das massas, construída no cotidiano do movimento real. A imensa confiança depositada na capacidade de organização das massas aparece de forma explícita nas formulações de Luxemburgo $(1991,2005)$.

A "Rosa vermelha do socialismo" (LOUREIRO, 2005) ou a "águia polonesa", como se referiu Lênin em homenagem póstuma a Luxemburgo, defendia a inexistência de qualquer dicotomia entre a ação espontânea e a ação consciente. É na própria luta concreta que reside o nascedouro da consciência, moldada e construída a partir da experiência das massas. Somente no processo de experimentar-se na ação, e não de maneira preliminar, podem ser forjadas as tarefas postas para a luta de classes em determinado momento histórico. Essa defesa fundamentava-se, primeiro, na concepção de Rosa Luxemburgo de que não são as organizações que desencadeiam o processo revolucionário, o qual requer a conjugação de uma complexa série de fatores econômicos, políticos e sociais; segundo, na sua compreensão de que não há uma única forma de organização posta para a classe trabalhadora. Desse modo, as experiências vividas - as derrotas ainda mais do que as vitórias da própria classe - são determinantes para a passagem do elemento espontâneo ao elemento consciente, presente na ação política da classe trabalhadora, materializada e condensada nos mais diversos movimentos sociais, políticos e culturais circunscritos no campo popular.

A iniciativa de ruptura com a dominação-exploração capitalista inscreve-se no campo de luta das próprias massas e não nas decisões do partido e de sua vanguarda. A realização do socialismo seria, portanto, uma tarefa a exigir:

[...] uma completa transformação do Estado e uma completa mudança nos fundamentos econômicos e sociais da sociedade [...] 'só a própria massa popular pode empreendê-las e realizá-las' [...]. A massa do proletariado é chamada não só para fixar claramente o objetivo e a orientação da revolução, mas também para 
que ela mesma, passo a passo, através da sua própria atividade, dê vida ao socialismo (LUXEMBURGO, 1991, p. 63, grifos das autoras).

Às massas, organizadas e mobilizadas, cabe realizar as mudanças e transformações societárias. A ênfase, proclamada por Rosa Luxemburgo, na importância da experiência das massas na sua própria conscientização, não nos autoriza, contudo, a atribuir ao seu pensamento qualquer princípio anarquista. Não há uma rejeição à organização, há uma concepção de partido, distinta daquela de Lênin. Para Luxemburgo, embora o partido não tenha o papel de desencadear a ação revolucionária, ele cumpre o papel de vanguarda, na medida em que detém a percepção do movimento de (re)produção capitalista e do lugar ocupado pela classe trabalhadora neste processo. O partido não pode em nenhuma ocasião substituir as massas; ele deve ser porta-voz de seus anseios, intérprete de suas vontades. Rosa fortalece o debate acerca dos princípios partidários e dos métodos organizativos para mobilizar as massas à participação e ao envolvimento com os processos de luta revolucionários.

\section{Gramsci: a construção de uma nova hegemonia e a ampliação da noção de política}

As contribuições de Antônio Gramsci somam-se ao leque de reflexões marxistas que influenciam as análises sobre os movimentos sociais. Este autor se destaca dentre os que mais contribuíram para a análise das lutas e dos movimentos populares urbanos realizados na América Latina, nos anos 1970 e início dos anos 1980 (SCHEREN-WARREN, 1987; GOHN, 2007; COUTINHO, 1988, 1989).

Para o pensador italiano, a reflexão sobre a organização política não pode prescindir da discussão sobre a divisão da sociedade em classes antagônicas. Com efeito,

[...] governados e governantes, dirigidos e dirigentes existem realmente. Toda ciência e arte da política se baseiam nesse fato primordial, irredutível (em determinadas condições gerais) [...] a seguinte premissa é fundamental: queremos que governados e governantes existam sempre ou queremos criar condições para que a necessidade dessa divisão desapareça? Partiremos do princípio de que a perpétua divisão do gênero humano é inevitável ou acreditaremos que ela seja apenas um fato histórico que responde a determinadas condições? (GRAMSCI, 2005, p. 11-12).

Assim, a organização e a luta política são pensadas na perspectiva de superação da sociedade de classes e da construção de outra sociabilidade radicalmente diferente. Neste sentido, Gramsci refere-se à necessidade de organização da classe para a construção de uma nova hegemonia, entendida aqui como direção/domínio e consenso ideológico (mas não somente) exercido por uma classe sobre a sociedade. Para tanto, indica estratégias anticapitalistas com o objetivo de levar a classe trabalhadora a ascender ao poder político, a exemplo, da "guerra de movimento e da guerra de posição". Didaticamente, podemos dizer que a primeira constitui uma forma de enfrentamento direto com o poder do Estado, enquanto a segunda se caracteriza por conquistas contínuas de espaços de direção ideopolíticos. Não obstante, para não extrairmos o caráter dialético da formulação gramsciana, é importante percebermos a guerra de posição como uma modalidade de enfrentamento com o Estado, sob outro formato. Na mesma linha de raciocínio, a guerra de movimento, constituindo igualmente um enfrentamento direto, não se restringe a este, na medida em que representa $\mathrm{e}$ aponta para a construção das tarefas mais imediatas, na perspectiva da organização da classe.

Para Gramsci (1999-2002), a construção de uma hegemonia das classes subalternas requer uma intensa "preparação ideológica das massas", um trabalho de construção de uma nova concepção de mundo. Dessa forma, a partir de determinada compreensão do processo de transformação social, Gramsci amplia, consideravelmente, a noção de política ao se preocupar com os elementos de preparação das condições ideológicas da práxis revolucionária, sem perder de vista a importância da articulação e complementariedade dos processos cultural e econômico, entendendo este último como determinante para a compreensão da realidade social e para sua transformação. Distingue duas formas de política: a grande política, ações que intencionam modificar ou preservar a ordem social, e a pequena política, ações vinculadas a questões parciais e cotidianas, como a política parlamentar. No complexo processo de passagem da pequena para a grande política ou ainda da consciência e da prática egoístico-passional para a ético-política constitui-se a esfera da política em Gramsci (DURIGUETTO, 2007).

O pensador italiano ressignifica, ainda, o conceito de sociedade civil, tornando o debate mais complexo. Em contraponto às posições que consideram a sociedade civil funcional ao projeto capitalista, a acepção gramsciana a concebe como a esfera em que as classes organizam e defendem seus interesses e disputam hegemonia. A sociedade civil passa a ser, portanto, 
[...] palco de um pluralismo de organismos coletivos ditos 'privados' (associações e organizações, sindicatos, partidos, atividades culturais, meios de comunicação etc.), é a nova configuração da dinâmica social, na qual se precisava repensar a política (DURIGUETTO, 2007, p. 55).

Assim, Gramsci demarca uma diferença radical de posição com relação a acepções dominantes de sociedade civil e, consequentemente, defende a construção de projetos políticos a partir deste entendimento.

O sentido de retomar as formulações de Lênin, Rosa Luxemburgo e Gramsci não se encerra na relevância teórica de suas análises, apesar desta dimensão em si ser bastante significativa para a luta política. O objetivo é, também, extrair destes autores inspiração para identificar questões e desafios postos aos movimentos sociais no tempo presente.

\section{Considerações finais}

Não se trata de aplicar de forma mecânica estas elaborações teóricas dos marxistas clássicos aos processos históricos atuais, mas de reconhecer sua atualidade, uma vez que ainda hoje ecoam e exercem influência na construção da estratégia de boa parte dos movimentos, partidos e organizações de esquerda. As ideias e noções desenvolvidas por Lênin, Rosa Luxemburgo e Gramsci continuam constituindo subsídios fundamentais, por exemplo, para a análise das relações entre as classes sociais, das vias prováveis para o desenvolvimento da revolução e de suas características, elementos historicamente presentes nas resoluções políticas das organizações de esquerda. Ademais, estes autores também contribuem para desvelar distintas questões a serem enfrentadas pelos movimentos sociais na atualidade. Os três conceitos fundamentais que extraímos das formulações de Lênin, Rosa Luxemburgo e Gramsci, quais sejam, a teoria da organização, a ampla participação das massas e a construção de uma nova hegemonia, ajudam-nos a refletir, particularmente, sobre três processos inter-relacionados presentes no cotidiano dos movimentos sociais contemporâneos, em suas diversas formas de luta e de resistência classistas.

O primeiro refere-se à relação entre movimentos e partidos políticos. Aqui, a preocupação mais comumente apontada pela militância dos movimentos sociais diz respeito à perda de autonomia do movimento, à medida que este pode se distanciar de seus próprios objetivos para atender apenas aos objetivos do partido. Ao se contrapor ao aparelhamento do movimento por parte dos partidos, tais posturas podem denotar uma perspectiva de autonomia "estrito senso", ou seja, negar a necessidade de articulação com organizações partidárias de esquerda. Tal posicionamento expressa, em grande medida, a cultura política brasileira na qual há uma visão negativa dos partidos e tem implicações sobre as relações entre partidos de esquerda e movimentos sociais e sobre a representatividade de ambos na atualidade.

O segundo diz respeito às dificuldades contemporâneas de organização e mobilização das massas, em um cenário de ampliação do desemprego, precarização do trabalho e agravamento da pobreza. Por certo, reconhecemos que a realidade está prenhe de focos de resistência classista, com diversos sujeitos coletivos empreendendo lutas concretas em prol dos interesses das classes subalternas. Todavia, não podemos negar que as transformações ocorridas no mundo do trabalho e na dinâmica de produção capitalista, nas últimas décadas, operaram alterações substantivas no seio da classe trabalhadora e produziram um cenário de inúmeras dificuldades para a organização política crítica e combativa. Ora, em tempos adversos para as lutas do trabalho em contraponto aos ditames do capital, os ganhos e avanços conquistados pelos movimentos sociais, em seus processos de luta, têm se caracterizado por serem muito mais de cunho político e ideológico (no sentido de avanço no processo de consciência coletiva e de disposição para organizar-se politicamente) do que propriamente concretos. Afinal, vivemos um tempo de reformismos de contrarreformas. Neste contexto, verificamos uma tendência predominante à mobilizações que visem à manutenção dos direitos historicamente conquistados, em detrimento da ação política em torno de um projeto societário, envolvendo os diversos movimentos de esquerda.

O terceiro relaciona-se diretamente à própria política por se tratar da construção de uma contra-hegemonia, isto é, do próprio processo de, por um lado, empreender a crítica teórica e prática à dominação capitalista e, por outro lado, construir as possibilidades de alteração desta realidade. A luta pela hegemonia de um projeto societário anti-capitalista, exige dos movimentos sociais a capacidade política de estabelecimento de alianças com outros sujeitos individuais e coletivos, mas também requer a capacidade de identificar os mecanismos de atuação da direita. Tomando o caso da direita brasileira, é necessário atenção especial para suas formas históricas de ação política, que aliam convencimento e apassivamento das pressões sociais com a peculiar e histórica truculência, que sempre marcou seu modo de tratar os interesses e os movimentos da classe trabalhadora.

Esta realidade impõe, assim, imensos desafios para a articulação e materialização das bandeiras de luta da classe trabalhadora, pois o esforço direitista interpõe-se justamente no sentido de invisibilizar e despolitizar as 
contradições sociais e as lutas políticas. Com efeito, o braço coercitivo do capital evidencia-se e atua justamente nos momentos de grandes acirramentos políticos e de confronto, nos quais sua hegemonia é questionada. A coerção e as mais graves formas de violência ocorrem, sobremodo, nas ocasiões em que os conflitos de classe ganham as ruas, em formas de protestos, reivindicações e politização das demandas e dos interesses do trabalho.

No nosso entendimento, esses processos sinalizam importantes desafios para as lutas sociais no capitalismo contemporâneo: a) o estabelecimento de uma relação verdadeiramente democrática entre movimentos e partidos, que considere as singularidades de organização e de interesses de ambos, superando tanto os isolamentos quanto as práticas vanguardistas; b) a identificação dos mecanismos engendrados pela atuação da direita brasileira na atualidade, que se mantém firme na defesa de uma agenda própria, contemplando privilégios e interesses das elites, como também investindo, pesadamente, na criminalização dos movimentos sociais e c) a construção de uma unidade das forças populares e, mais ainda, a mobilização das energias de lutadores e lutadoras do povo, para a construção de força própria da classe trabalhadora, única alternativa real para derrotarmos os inimigos históricos da classe. Não nos rendamos, portanto, ao status de verdade irrefutável que parece ter adquirido o pensamento do fim da história. Tarefas primordiais e plenas de atualidade para a organização da classe nos são impostas.

\section{Referências}

BIRH, A. Da grande noite à alternativa: o movimento operário europeu em crise. Tradução de Walda Caldeira Brant. São Paulo: Boitempo, 1998.

BRAZ, M. Partido e revolução: 1848-1989. São Paulo: Expressão Popular, 2011.

CASTELLS, M. Movimientos sociales urbanos. Madrid: Siglo XXI, 1974.

COUTINHO, C. N. As categorias de Gramsci e a realidade brasileira. In: COUTINHO, C. N.; NOGUEIRA, M. A. (Org.). Gramsci e a América Latina. Rio de Janeiro: Paz e Terra, 1988, p. 103-128.

. Gramsci: um estudo sobre seu pensamento político. Rio de Janeiro: Campus, 1989.

DURIGUETTO, M. L. Sociedade civil e democracia: um debate necessário. São Paulo: Cortez, 2007.

DURIGUETTO, M. L.; MONTAÑO, C. Estado, classe e movimento social. São Paulo: Cortez, 2010.

GOHN, M. da G. Teorias dos movimentos sociais: paradigmas clássicos e contemporâneos. São Paulo: Loyola, 2007.

GRAMSCI, A. Cadernos do cárcere, 6 v. Edição de Carlos Nelson Coutinho, com a colaboração de Luiz Sérgio Henriques e Marco Aurélio Nogueira. Rio de Janeiro: Civilização Brasileira, 1999-2002.

Cartas do cárcere, v. 2. Organizado por Luiz Sérgio Henriques com a colaboração de Carlos Nelson Coutinho. Rio de Janeiro:

Civilização Brasileira, 2005.

GUIMARÃES, M. C. R. Movimentos e lutas sociais na realidade brasileira. Revista Debate e Sociedade, Uberlândia, v. 2, p. 18-37, 2011.

KONDER, L. O marxismo na batalha das ideias. São Paulo: Expressão Popular, 2009.

LACLAU, E; MOUFFE, C. Hegemonia y estrategia socialista: hacia una radicalizacíon de la democracia. Madrid: Siglo XXI, 1988.

LEFEBVRE, H. (Org.). A irrupção: a revolta dos jovens na sociedade industrial, causas e efeitos. São Paulo: Ed. Documentos, 1968.

LÊNIN, V. I. O Estado e a revolução. Tradução de Aristides Lobo. Rio de Janeiro: Editorial Vitória, 1961.

. L'impérialisme, stade suprême du capitalisme. Paris-Moscou: Editions Sociales/Editions du Progrès, 1975.

O marxismo e a insurreição: carta ao comitê central do POSDR. Tradução do Instituto de Marxismo-Leninismo de Moscou.

São Paulo: Alfa-omega, 1980. (Obras escolhidas, v. 2)

. Carta a um camarada. In: . As três fontes. Tradução de Paulo Alves de Lima Filho. São Paulo: Expressão Popular, 2006, p. 21-22.

Que fazer? Problemas candentes do nosso tempo. Tradução de Marcelo Braz. São Paulo: Expressão Popular, 2010.

LOJKINE, J. O Estado capitalista e a questão urbana. Tradução de Estela dos Santos Abreu. São Paulo: Martins Fontes, 1981.

LOUREIRO, I. M. Rosa Luxemburgo: vida e obra. São Paulo: Expressão Popular, 2005.

LUXEMBURGO, R. A Revolução Russa. Tradução de Isabel Maria Loureiro. Petrópolis: Vozes, 1991.

. Greve de massas, partidos e sindicatos. In: BOGO, A. (Org.). Teoria da organização política: escritos de Engels, Marx, Lenin,

Rosa, Mao. São Paulo: Expressão Popular, 2005, p. 241-337.

MARX, K. Contribuição à crítica da economia política. Tradução de Florestan Fernandes. São Paulo: Expressão Popular, 2008.

MARX, K.; ENGELS, F. Manifesto do partido comunista. Tradução de Victor Hugo Klagsbrunn. São Paulo: Expressão Popular, 2008.

SALEM, J. Lênin e a revolução. São Paulo: Expressão Popular, 2008.

SADER, E. (Org.). Gramsci: poder, política e partido. São Paulo: Expressão Popular, 2005.

SANTOS, B. de S. Pela mão de Alice: o social e o político na pós-modernidade. São Paulo: Cortez, 1999.

. Os novos movimentos sociais. In: LEHER, R.; SETÚBAL, M. (Org.). Pensamento crítico e movimentos sociais: diálogos para uma nova práxis. São Paulo: Cortez, 2005, p. 174-189. 
SCHEREN-WARREN, I. Movimentos sociais: um ensaio de interpretação sociológica. Florianópolis: Editora da UFSC, 1987.

TOURAINE, A. Os novos conflitos sociais: para evitar mal-entendidos. Tradução de Marili da Cunha Bezerra. Lua Nova, São Paulo: Cedec, n. 17, p. 5-18, 1989.

\section{Notas}

1 Para umestudo comparativo entre as teorias dos movimentos sociais, pondoem evidência suas diferenças e semelhanças, indicamos a leitura de Touraine (1989) como expoente da teoria acionalista; Laclau e Mouffe (1988) e Santos (1999, 2005) como representantes da abordagem pós-moderna; Castells (1974)eLojkine (1981) como autores que figuram dentre os primeiros estudiosos a empreender esforço teóricona análise dos movimentos sociais atuais, em uma perspectiva marxista. Uma sistematização acerca do conjunto destas teorias pode ser encontrada nas obras de Gohn (2007) e Scheren-Warren (1987). Contrariamente à análise de Gohn, consideramos que o nominado "Paradigma dos novos movimentos sociais" não pode ser reputado como exclusivamente pós-moderno ou acionalista, pois há autores marxistas, a exemplo de Lefebvre (1968) e Birh (1998), que também utilizam a mesma denominação para se referir a alguns movimentos sociais, sem necessariamente despi-los do caráter classista. Contudo, reconhecemos que, apartirdos anos 1990, há crescente influência pós-moderna na concepção dos "novos" movimentos sociais.

2 Afirmamos tratar-se de duas grandes tendências teóricas porque, especialmente, no que se refere ao debate acerca dos movimentos sociais no Brasil, concordamos com a análise de Duriguetto e Montaño (2010), segundo a qual as vertentes acionalista e pós-moderna parecem hoje estar fundidas num verdadeiro "rearranjo culturalista".

3 O prefácio de Marx à Contribuição à crítica da economia política é, não por acaso, bastante reforçado por Lênin: "Em uma certa etapa de seu desenvolvimento, as forças produtivas materiais da sociedade entram em contradição com as relações de produção existentes, ou, o que nãoé mais que sua expressão jurídica, com as relações de propriedade no seio das quais elas se haviam desenvolvido até então. De formas evolutivas das forças produtivas que eram, essas relações convertem-se em entraves. Abre-se, então, uma época de revolução social. A transformação que se produziu na base econômica transforma mais ou menos lenta ou rapidamente toda a colossal superestrutura" (MARX, 2008, p. 45).

4 Em alguns momentos, a exemplo de Lênin, Gramsci (2005, p. 68) compara luta política e arte militar, mas reconhece que: "[...] a luta política é enormemente mais complexa".

\section{Maria Clariça Ribeiro Guimarães}

clarica.ribeiro@gmail.com

Mestre em Serviço Social pela Universidade Federal do Rio Grande do Norte (UFRN)

\section{Eliana Costa Guerra}

elianacostaguerra@hotmail.com

Doutora em Sociologia pela Universidade de Paris VIII

Professora do Departamento de Serviço Social e do Programa de Pós-Graduação em Serviço Social da UFRN

\section{UFRN - Centro de Ciências Sociais Aplicadas}

Campus Universitário Lagoa Nova

Lagoa Nova

Natal - Rio Grande do Norte - Brasil

CEP: 59072-970 